\title{
Fuelwood energy characteristics and biomass equations of the dominant species of northern Patagonian shrublands (Argentina)
}

\author{
Matías G Goldenberg ${ }^{1,2 *}$, Yamila A Cardoso ${ }^{1}$, Facundo J Oddi ${ }^{1,2}$ and Lucas A Garibaldi ${ }^{1,2}$ \\ 1 Instituto de Investigaciones en Recursos Naturales, Agroecología y Desarrollo Rural (IRNAD), Sede Andina, Universidad \\ Nacional de Río Negro, San Carlos de Bariloche, Argentina \\ ${ }^{2}$ Consejo Nacional de Investigaciones Científicas y Técnicas (CONICET), San Carlos de Bariloche, Argentina \\ ${ }^{*}$ Corresponding author, email: mgoldenberg@unrn.edu.ar
}

\begin{abstract}
Although shrublands can be highly abundant, their bioenergy potential has barely been addressed. This is the case in northern Patagonian shrublands, where there is a lack of knowledge regarding biomass quantity and quality. The objective of this study was to develop biomass equations for young shoots (resprouts) of five of the main woody species growing in northern Patagonian shrublands; quantify energy properties of their woods and, ultimately, estimate biomass and bioenergy stocks in resprouts for three contrasting shrublands. Resprouts were harvested in the field, and size (diameter and height) and dry weight were measured in the laboratory. Fuelwood energy parameters (moisture, density, calorific value, ash content) were determined to obtain energy density and fuelwood value index. We found biomass equations with good statistical fitness for all the studied species. Energy parameters of the analysed woods were comparable or even better (in terms of energy density) than those observed in other woody species commonly used as fuels. Embothrium coccineum showed the best fuelwood value index due to low ash content $(0.2 \%)$. Shrublands under $50 \%$ of harvesting intensity produced $0.08 \mathrm{t} \mathrm{ha}^{-1}$ and $1.33 \mathrm{GJ}^{\mathrm{h}} \mathrm{ha}^{-1}$ in a low productivity site, $0.34 \mathrm{t} \mathrm{ha}^{-1}$ and $5.66 \mathrm{GJ} \mathrm{ha}^{-1}$ in a medium productivity site, and $1.07 \mathrm{t} \mathrm{ha}^{-1}{\text { and } 17.96 \mathrm{GJ}^{-1}}^{-1}$ in a high productivity site from resprouts after approximately four years. This study suggests that some northern Patagonian shrublands have good potential to produce high quality biomass, therefore, sustainable management plans oriented to bioenergy should be developed in the region.
\end{abstract}

Keywords: bioenergy, native forest, biomass models, calorific value

Introduction

Forest biomass for energy generation is receiving great attention worldwide. It is a source of renewable energy that can be neutral in terms of carbon dioxide emission balance (Abbasi and Abbasi 2010). These characteristics are important in the face of the current challenge represented by Global Change, since it reduces the dependency on nonrenewable energy sources (Panwar et al. 2011). In addition, it can contribute to increasing and diversifying the energy matrix of countries, which is key for sustainable development.

Though shrublands have suitable properties for energy production, and biomass derived from these ecosystems is gaining importance (González-González et al. 2017), they have historically been replaced by afforestation with fast-growing exotic species managed for industrial purposes (Schlichter and Laclau 1998). For instance, in these ecosystems the knowledge about energy characteristics of biomass is limited. Hence, the generation of basic information about the quantity and energy quality of shrubland woody biomass is key to draw up energyoriented management schemes (Singh and Khanduja 1984). Indeed, this forest type has the potential of complementing biomass derived from clearing, thinning or pruning of fast-growing plantations (Karp and Shield 2014).

The native mixed shrublands of northern Patagonia, a Mediterranean climate-type region, have favourable characteristics to produce woody biomass. They are dominated by heliophile resprouting species, such as Nothofagus antarctica (Kitzberger and Veblen 1999). In addition, as for other pioneer species used for the purpose of supplying energy (e.g. Populus spp.), they exhibit high initial growth rates after disturbance (Tiribelli et al. 2018). Many of the northern Patagonian shrublands are close to the urban centres of the Río Negro province (Gowda 2013). These characteristics favour their use, by reducing distance-related energy and economic costs.

In northern Patagonia, information about the silviculture of shrubland communities is poor (Goldenberg et al. 2018, Grosfeld et al. 2019). A recently introduced forest Law (National Law 26.331) prohibits replacing native shrublands with exotic species, so sustainable management for woody fuel production could be a viable option. For this, biomass and bioenergy stock estimations become a critical issue. Volume and biomass equations have been developed for some species such as N. antarctica, Schinus patagonicus, Lomatia hirsuta and Diostea juncea (Reque et al. 2007; Gyenge et al. 2009), but not for young resprouts that could be important for developing short-rotation coppice systems. In addition, dominant shrubland species have not been characterised in terms of energy parameters. Such lack of biomass equations and of the characterisation of woody 
energy restricts the development of dendroenergy (Hilbert 2013).

There are several parameters for characterising wood as fuel. Among the parameters related to energy amount, moisture affects calorific value and is thus related to energy efficiency. Ash content has technological relevance, since it interferes with the combustion process, and increases the maintenance that is necessary for stoves and boilers. Calorific value quantifies the energy contained within woody mass, while wood density quantifies the mass contained in wood volume, so by combining these two variables it is possible to calculate energy density; i.e. woody volume energy (FAO 2017). Finally, the fuelwood value index is useful for comparing species, since it combines the previously mentioned parameters (it increases with energy density and decreases with ash and moisture content) (Purohit and Nautiyal $1984<A Q 3>$ ). However, none of these parameters have been systematically determined for northern Patagonian shrubland species.

In this study, we focus on N. antarctica, S. patagonicus, $L$. hirsuta, $D$. juncea and $E$. coccineum, the dominant species of northern Patagonian shrublands and aim to: (1) estimate species-specific biomass equations for young resprouts, derived from easy field measures; (2) quantify energy parameters of fuelwood and (3) estimate biomass and bioenergy stocks using three contrasting shrublands under experimental management as an example. We expect to contribute to management schemes for energy purposes in northern Patagonian shrublands, to ultimately contribute to Mediterranean forestry.

\section{Materials and methods}

\section{Study area}

In the Andean region of northern Patagonia, Argentina, there is an important area covered by pure and mixed $N$. antarctica shrublands. Although these communities are dominated by $N$. antarctica, they can also be co-dominated by S. patagonicus, L. hirsuta, D. juncea and E. coccineum (Gyenge et al. 2009). These are all resprouting woody species and can form the most diverse ecosystems of the region (Speziale et al. 2010). In the absence of fire and cattle, they are usually displaced by longer-lived species and obligate seed-dispersers such as Austrocedrus chilensis trees, forming pure forests (Kitzberger and Veblen 1999). Nonetheless, this dynamic is usually affected by fire due to the pyrolytic characteristics of these communities (i.e. fire-adapted forests) (Keeley et al. 2011; Blackhall et al. 2012).

El Foyel is a rural area located $73 \mathrm{~km}$ south of the town of

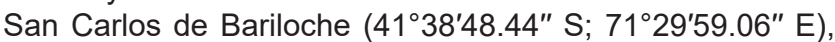
Río Negro province (Figure 1). In this area, where landscapes are characterised by large shrubland patches, the Instituto de Investigaciones en Recursos Naturales, Agroecología y Desarrollo Rural (IRNAD) from Universidad Nacional de Río Negro (UNRN) started a long-term monitoring experiment between 2013 and 2014, in which several plots were harvested in strips ( 2 hectares in total).

\section{Field sampling}

Field sampling was carried out in spring. The selected species where: N. antarctica, L. hirsuta, S. patagonicus, D. juncea

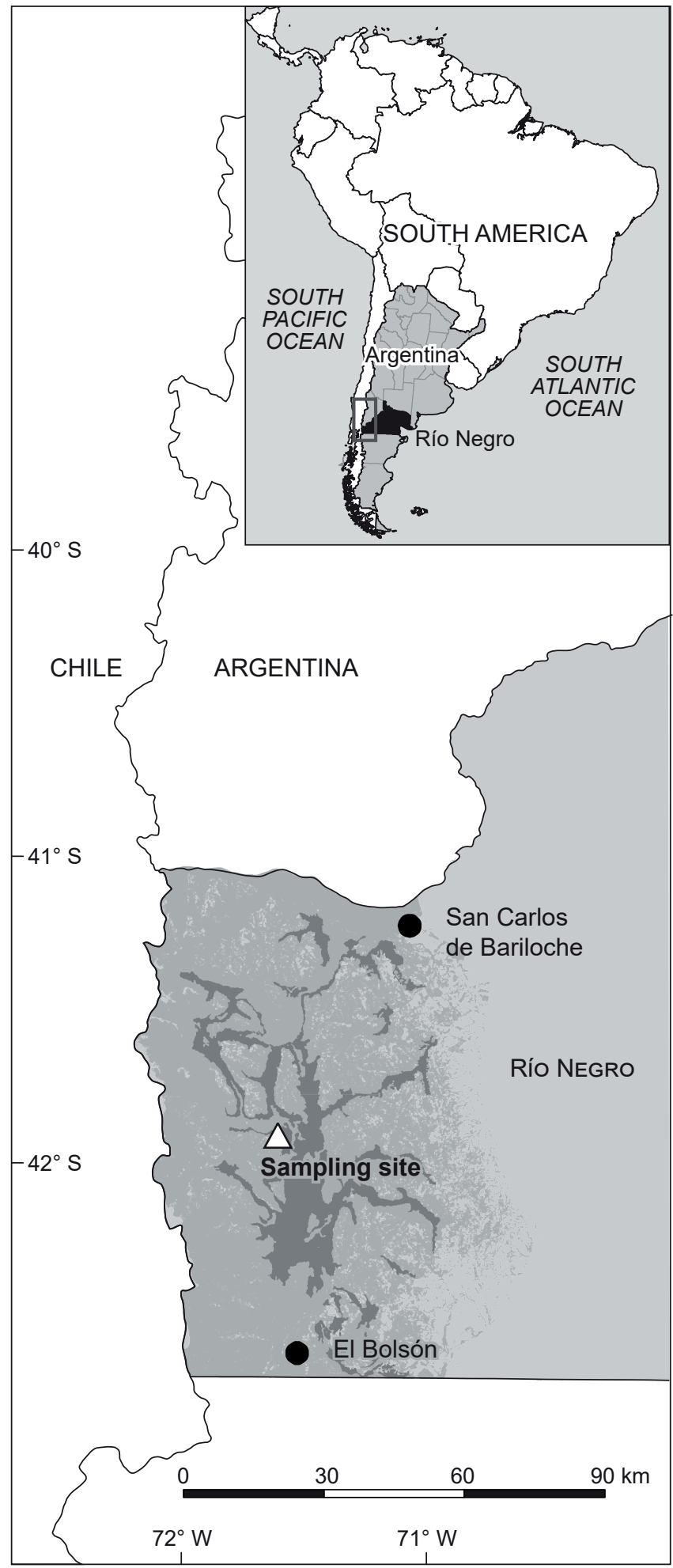

Figure 1: Sampling site location (El Foyel) in Río Negro province, northern Patagonia, Argentina. Dark grey represents the shrubland distribution and light grey tall forests distribution.

and $E$. coccineum. Three adult individuals per species were randomly selected $(n=15)$ within the remaining vegetation (i.e. from the non-harvested zone). In each sampled 
individual, two $2 \mathrm{~cm}$ diameter discs (cross sections) and one $\sim 15 \mathrm{~cm}$ diameter piece of log were extracted. All the materials were placed in hermetic plastic bags and taken to the laboratory. For the stem discs, wood moisture and density were determined. Aliquots of the small logs were prepared to determine ash content and calorific value.

To develop the biomass equations, during the summer, within coppice regrowth strips, 10 to 17 resprouts aged $\approx 4$ years (i.e. sticks) per species were randomly selected and harvested to be weighted and analysed in the laboratory. Additionally, in the coppiced strips, four individuals per species in each plot were randomly chosen, and the number of resprouting stems (greater than $0.4 \mathrm{~cm}$ in diameter) per stool was counted (Table 1). Of these stems, five were randomly selected and stem base diameter (SBD, $3 \mathrm{~cm}$ from the insertion point to the stump) and total height were measured (Table 1) to estimate stem dry weight (W). This last procedure was repeated in two plots in three contrasting sites of high $(\mathrm{H})$, medium $(\mathrm{M})$ and low $(\mathrm{L})$ levels of productivity that were a part of a larger experiment (for more detailed information see Coulin et al. 2019). Table 1 summarises mean values (from two replicates) of each variable measured for the three sites.

\section{Laboratory analysis}

Measurements of resprouts used in biomass equations were obtained from the main stem of the leafless harvested resprouts (between 10 and 17 for each species), and when this was difficult to determine (e.g. due to bifurcations, pitchforks, etc.), the longest stem was selected. For each stem, the height $(\mathrm{H})$ and diameter $3 \mathrm{~cm}$ from the insertion to the stump (SBD) were recorded. Harvested stems were dried to constant weight and weighted $(\mathrm{W})$ with a precision balance $(0.01 \mathrm{~g})$.

To quantify moisture, the indirect gravimetric method was applied. The dry weight was obtained by drying the material in an oven until it reached constant weight. Moisture was calculated on a dry basis $\left(m_{d b}\right)$ (Equation 1$)$.

$$
m_{d b}=\frac{w_{w}-d_{w}}{d_{w}} \times 100
$$

where $w_{w}$ is wet weight in $\mathrm{g}$; and $d_{w}$ is dry weight in $\mathrm{g}$.

Wood density $(d)$ was obtained by means of the water displacement method (Olesen 1971) (Equation 2).

$$
d=\left(\frac{d_{w}}{w_{p}}\right) \times w_{d}
$$

where $d_{w}$ is dry weight in $\mathrm{g} ; w_{p}$ is the weight of the liquid displaced or pushed by the sample submerged in $\mathrm{g}$; and $w_{d}$ is water density in $\mathrm{g} \mathrm{cm}^{-3}$.

To determine ash content, aliquots from the log pieces were oven-dried for 48 hours, pulverised using a rasp, and sieved with a $\mathrm{N}^{\circ} 35$ mesh. Then, the material, placed on porcelain capsules, was put into a muffle for 4 hours at $550{ }^{\circ} \mathrm{C}$ for its complete incineration. Finally, ash content was determined on a dry basis $\left(A C_{d b}\right)$ (Equation 3$)$.

$$
A C_{d b}=\frac{C_{c+c e}-C_{c}}{C_{c+m}-C_{c}} \times 100
$$

where $c_{c}+{ }_{c e}$ is the weight of the capsule plus that of the resulting ashes in $\mathrm{g} ; \underline{c}_{\underline{c}}$ is the weight of the capsule in $\mathrm{g}$; and $C_{c}{ }{ }_{m}$ is the weight of the capsule plus that of the dried material in $\mathrm{g}$.

Higher and lower calorific values (HCV and LCV, respectively) were determined. The difference between these values depends on the way in which the water vapour generated during combustion is treated: If after combustion the latent heat generated by water vapour is accounted for, the HCV is obtained (Eimil-Fraga et al. 2019); but if, instead, water vapour is lost along with other combustion gases, LCV is obtained. HCV was determined using a Mahler calorimeter pump. In each determination, $1 \mathrm{~g}$ of powder was used following the test protocol of IRAM 17016 and DIN 51900-1-2000. HCV (cal g ${ }^{-1}$ ) was obtained according to the following expression (Equation 4):

$$
\mathrm{HCV}=\frac{\mathrm{E} \times \Delta T-\left(c_{1}+c_{2}+c_{3}\right)}{m_{c}}
$$

where $\mathrm{E}$, the calorimeter water equivalent $\left(2328 \mathrm{cal}{ }^{\circ} \mathrm{C}^{-1}\right)$, does not depend on the test; $\Delta T$ is the temperature variation reached $\left({ }^{\circ} \mathrm{C}\right) ; c_{1}$ is a correction factor for nitric acid; $c_{2}$ is a correction factor for sulphur content; $c_{3}$ is the correction for the Nichrome wire used; and $m_{c}$ indicates fuel mass ( $1 \mathrm{~g}$ was used). LCV (cal g ${ }^{-1}$ ) was obtained based on the following expression (Aniszewska and Gendek 2014) (Equation 5):

Table 1: Mean values of SBD, height, number of stems per plant and number of plants respurting in plots after $50 \%$ of harvesting intensity for three contrasting shrublands $(\mathrm{H}, \mathrm{M}$ and $\mathrm{L})$.

\begin{tabular}{llcccc}
\hline Site & \multicolumn{1}{c}{ Species } & $\begin{array}{c}\text { Mean } \\
\text { SBD }(\mathrm{cm})\end{array}$ & $\begin{array}{c}\text { Mean } \\
\text { height }(\mathrm{cm})\end{array}$ & $\begin{array}{c}\text { Mean no. of } \\
\text { stems per plant }\end{array}$ & $\begin{array}{c}\text { No. plants } \\
\left(\text { pl. ha }{ }^{-1}\right)\end{array}$ \\
\hline $\mathrm{H}$ & N. antarctica & 1.05 & 121.0 & 10.0 & 541 \\
& L hirsuta & 1.59 & 132.5 & 15.5 & 167 \\
& S. patagonicus & 1.22 & 111.0 & 18.5 & 501 \\
& D. juncea & 1.26 & 168.0 & 24.0 & 167 \\
& E. coccineum & 1.05 & 128.9 & 11.5 & 231 \\
\hline $\mathrm{M}$ & N. antarctica & 0.99 & 98.8 & 12.5 & 370 \\
& L hirsuta & 1.08 & 87.4 & 16.5 & 114 \\
& S. patagonicus & 0.86 & 70.9 & 13.0 & 343 \\
& D. juncea & 1.29 & 164.9 & 9.0 & 114 \\
& E. coccineum & 0.86 & 97.2 & 14.0 & 58 \\
\hline $\mathrm{L}$ & N. antarctica & 0.53 & 41.3 & 7.0 & 2122 \\
\hline
\end{tabular}




$$
\mathrm{LCV}=(\mathrm{HCV}-49.28 \times H) \times \frac{100-m_{f}}{100-m_{s}}-23 \times m_{1}
$$

where $\mathrm{H}$ is fuel hydrogen content $(\%) ; m_{f}$ is fuel moisture content (\%); and $m_{s}$ is moisture content of the sample used to calculate HCV (\%). Because LCV was calculated on a dry basis $\left(m_{f}=0\right)$ and using dry material $\left(m_{s}=0\right)$, the previous expression was reduced to the following (Equation 6):

$$
\mathrm{LCV}_{m 0}=\mathrm{HCV}-49.28 \times H
$$

$H$-values for $L$. hirsuta and $N$. antarctica samples $(6.1 \%$ and $5.4 \%$ respectively) were obtained from literature. Since no information was found for the other studied species, the average $(5.9 \%)$ of other native species of the region for which $\mathrm{H}$ is reported was used (Carmona-Cerda and AlvaroUrzua 2013). HCV and LCV were re-expressed as $\mathrm{MJ} \mathrm{kg}^{-1}$.

Finally, energy density (ED) was calculated by multiplying LCV by the density $(E D=L C V \times d)$ and this value was used along with ash content and moisture to calculate the fuelwood value index (FVI) (Purohit and Nautiyal 1984) (Equation 7):

$$
\mathrm{FVI}=\frac{\mathrm{LCV} \times d}{A C_{d b} \times m_{d b}}
$$

\section{Statistical analysis}

Species-specific biomass equations were obtained by fitting multiple linear regressions with the $\mathrm{g} / \mathrm{s}$ function in $\mathrm{R} 3.5$ software (R Core Team 2017). In these models, resprout stem dry weight $(\mathrm{W})$ was the response variable and was modelled as a function of basal diameter (SBD), squared basal diameter $\left(\mathrm{SBD}^{2}\right)$, total height $(H)$, and squared total height $\left(H^{2}\right)$. For each species, we selected the best model based on the Akaike Information Criterion (AIC) (Garibaldi et al. 2017), using the dredge function of the MuMin package (Barton 2018). Assumptions of homoscedasticity and normality were checked by visual evaluation of the residual plots (e.g. residual vs. predicted values, $q-q$ plots) and Shapiro-Wilk, and Kolmogorov-Smirnov tests (shapiro.test and ks.test, respectively, in R software). When necessary, variances were modelled with the VarPower as a function of predicted values (Pinheiro et al. 2018).

Wood energy parameters were estimated by fitting linear models with species as the predictor variable (categorical variable with five levels). For among-species comparisons, an analysis of variance (ANOVA, $\alpha=0.05$ ) was performed, and a posteriori tests were applied when differences were detected (Tukey test, $\alpha=0.05$ ).

\section{Biomass and bioenergy stock estimations}

For each species, plant biomass stock of resprouts (g plant ${ }^{-1}$ ) was obtained by multiplying stem dry weight, estimated by the developed biomass equations using measured SBD and height as predictors (Table 1), by the average number of stems per stool resprouting for each species (Table 1). Then, biomass stock at plot level $\left(\mathrm{kg} \mathrm{ha}^{-1}\right)$ was obtained by multiplying plant biomass stock by number of plants resprouting (after $50 \%$ of harvesting intensity) following previous works (Table 1) (Goldenberg et al. unpubl. data) and bioenergy stock ( $\left.\mathrm{MJ} \mathrm{ha}^{-1}\right)$ by multiplying biomass stock by LCV. This was repeated for $\mathrm{H}$, $\mathrm{M}$ and $\mathrm{L}$ sites.

\section{Results and discussion}

\section{Biomass equations}

Overall, the models showed goodness of fit (Figure 2). Basal diameter and height were important in predicting stem weight. For all the species, weight showed a non-linear response with basal diameter and height (see equations in Figure 2). Variances increased with weight, and thus variance functions were applied in all the models to meet the model assumptions.

There are few studies quantifying biomass equations for lower diameter classes. Because biomass allocation patterns differ with tree age (Gargaglione et al. 2010), allometric equations generated from larger trees are not applicable to trees whose diameters or heights are beyond the fit range of a given model (Huber et al. 2017). Hence, our biomass equations complement those made by previous studies for the analysed community (Reque et al. 2007; Gyenge et al. 2009). Since we developed equations for juvenile resprouts, the diameter of the stem base (instead of diameter at breast height, 1.30 meters above the ground, $\mathrm{DBH}$ ) was used as a predictor. $\mathrm{DBH}$ could be a poor predictor of biomass for small trees (Wirth et al. 2004) since it could be located on the crown, even on bifurcated feet (Huber et al. 2017). For instance, in shrubs such as $D$. juncea, basal diameter (if greater than $3 \mathrm{~cm}$ ) is a better predictor of stem weight than DBH (Gyenge et al. 2009).

In agreement with previous studies, our work reveals that including height in biomass estimations is important for achieving more precise estimations (Joosten et al. 2004; Gargaglione et al. 2010; Cienciala et al. 2015). Although this implies additional fieldwork, incorporating this variable improves biomass estimation, which might have implications for management practices. For example, reliable measurements of biomass stock would allow the design of harvest cycles without compromising or underutilising the biomass resource.

\section{Wood energy characterisation}

In general, all the species showed an average of $80 \%$ moisture content. The highest wood moisture content was found in L. hirsuta (94\%); and the lowest moisture content was found in $D$. juncea (75\%) (Table 2). The other species did not statistically differ from these two (Table 2). Since efficient combustion requires a moisture content lower than $30 \%$ (BUN-CA 2002), our results suggest the woods of the analysed species should lose approximately $50 \%$ of moisture before being used as fuel. It is known that calorific power decreases linearly with moisture content (FAO 2017); thus, if firewood drying time is insufficient, wood would burn up inefficiently and more fuel would be needed to achieve the required energy. While relevant for bioenergy applications, log moisture temporal dynamics linked to drying time have not been studied in northern Patagonia.

The highest wood densities were found in N. antarctica, D. juncea and $S$. patagonicus $\left(530.1-564.6 \mathrm{~kg} \mathrm{~m}^{-3}\right)$, while the lowest values were observed in $E$. coccineum 

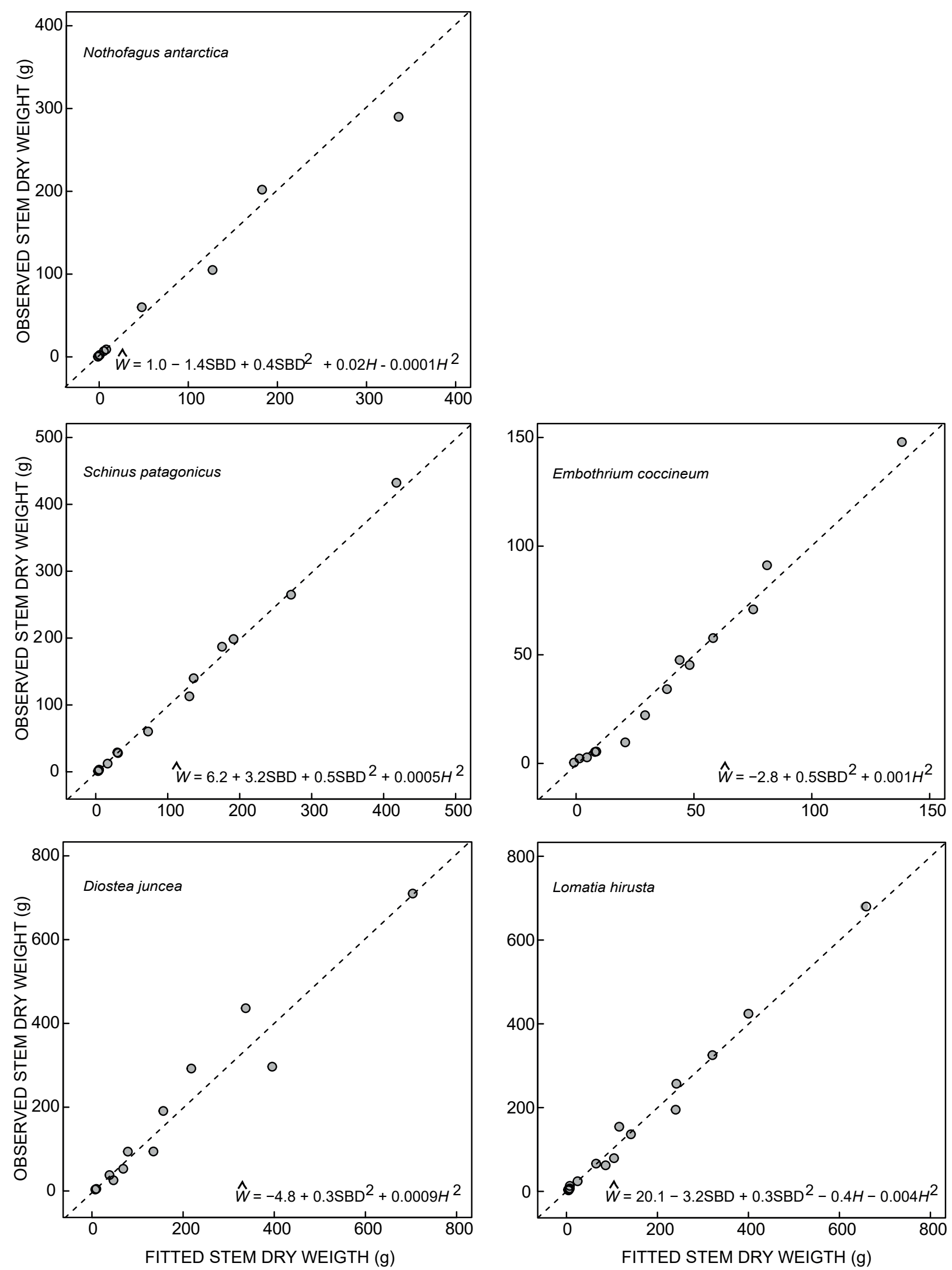

Figure 2: Observed vs. predicted values graphics showing the goodness of fit of the biomass equations developed for resprouts of five northern Patagonian native species. The selected model for each species is given in each plot. Stem dry weight $(W)$ was predicted as a function of linear and quadratic terms of stem basal diameter (SBD) and height $(H)$. In all cases VarPower function was used to model unequal variances. 
Table 2: Energy parameter estimates for the different species \pm standard deviation. For all parameters there was a significant effect of species under $F$-test of the ANOVA $(\alpha=0.05)$. Equal letters stand for no difference according to a posteriori Tukey test $(p \leq 0.05)$. AC: ash content; HCV: higher calorific value; LCV: lower calorific value; ED: energy density; FVI: fuelwood value index.

\begin{tabular}{|c|c|c|c|c|c|}
\hline \multirow{2}{*}{$\begin{array}{l}\text { Energy } \\
\text { parameter }\end{array}$} & \multicolumn{5}{|c|}{ Species } \\
\hline & L. hirsuta & E. coccineum & S. patagonicus & N. antarctica & D. juncea \\
\hline Moisture (\%) & $94.2 \pm 5.8^{\mathrm{a}}$ & $90.5 \pm 9.2^{\mathrm{ab}}$ & $87.4 \pm 3.2^{\mathrm{ab}}$ & $81.2 \pm 9.2^{\mathrm{ab}}$ & $75.4 \pm 5.5^{b}$ \\
\hline Density $\left(\mathrm{kg} \mathrm{m}^{-3}\right)$ & $462.7 \pm 22.2^{\mathrm{ab}}$ & $446.2 \pm 24.3^{b}$ & $530.1 \pm 12.5^{\mathrm{ac}}$ & $564.6 \pm 34.1^{c}$ & $551.5 \pm 35.7^{c}$ \\
\hline$A C(\%)$ & $0.7 \pm 0.4^{\mathrm{ab}}$ & $0.2 \pm 0.2^{b}$ & $2.1 \pm 0.6^{a}$ & $1.7 \pm 0.3^{\mathrm{ab}}$ & $1.2 \pm 0.9^{\mathrm{ab}}$ \\
\hline $\mathrm{HCV}\left(\mathrm{MJ} \mathrm{kg}^{-1}\right)$ & $19.6 \pm 0.06^{a}$ & $18.8 \pm 0.05^{b}$ & $18.1 \pm 0.06^{c}$ & $17.7 \pm 0.06^{d}$ & $17.3 \pm 0.1^{\mathrm{e}}$ \\
\hline LCV $\left(\mathrm{MJ} \mathrm{kg}^{-1}\right)$ & $18.3 \pm 0.06^{a}$ & $17.6 \pm 0.05^{b}$ & $16.8 \pm 0.06^{c}$ & $16.6 \pm 0.06^{d}$ & $16.0 \pm 0.1^{\mathrm{e}}$ \\
\hline $\mathrm{ED}\left(\mathrm{GJ} \mathrm{m}^{-3}\right)$ & $8.46 \pm 0.42^{\mathrm{ab}}$ & $7.86 \pm 0.4^{b}$ & $8.93 \pm 0.19^{a b}$ & $9.35 \pm 0.55^{a}$ & $8.84 \pm 0.6^{\mathrm{ab}}$ \\
\hline FVI & $1755.6 \pm 1316.3^{a b}$ & $6964.1 \pm 4339.3^{a}$ & $507.7 \pm 105.5^{b}$ & $692.6 \pm 33.4^{b}$ & $1341.7 \pm 696.5^{b}$ \\
\hline
\end{tabular}

and L. hisuta (446.2-462.7 $\left.\mathrm{kg} \mathrm{m}^{-3}\right)$. Differences between $N$. antarctica, $D$. juncea and $S$. patagonicus were not statistically significant (Table 2); while the observed values in $E$. coccineum and $L$. hirsuta were, on average, about $18 \%$ lower (Table 2). These results suggest that Patagonian shrubland species have higher wood density than that of Populus spp. (Kauter et al. 2003) or $P$. ponderosa afforestations (Andreassi et al. 2017), whose thinning residues are used as firewood in the region (Andreassi et al. 2017). In particular, the N. antarctica was the species with the highest density (Table 2), although the estimated value (Table 2) was lower than one previously reported (Solórzano-Naranjo 2017). However, both values might not be directly comparable, since wood density varies with age and bark thickness (Senelwa and Sims 1999), and the previous study mentioned sampled tree-type individuals growing in tall forests (SolórzanoNaranjo 2017). The wood density of the remaining species analysed in our study were within the range reported for other native species of the region (Carmona-Cerda and Alvaro-Urzua 2013). The high density of logs implies that charcoal would remain lit for long time, increasing heating time (Abbot and Lowore 1999).

E. coccineum was the species with the lowest ash content $(0.2 \%)$, while the highest value was observed in S. patagonicus $(2.1 \%)$ and was $\approx 10$ times higher. The other species did not statistically differ from these two (Table 2). Indeed, ash content was the energy parameter with the greatest relative variability among species. Nonetheless, ash content of all the analysed species was below $2 \%$ (Table 2 ), except for $S$. patagonicus. In $N$. antarctica $(1.7 \%)$ and $L$. hirsuta $(0.7 \%)$ ash content was higher than the values reported in the literature $(1.3 \%$ and $0.5 \%$, respectively) (Carmona-Cerda and Alvaro-Urzua 2013; Solórzano-Naranjo 2017). However, unlike such studies, our analysis included the bark, which increases ash content (Ragland et al. 1991) and which is usually a component of firewood and chips.

Regarding calorific values, differences were found among all species. The species with the highest HCV was the L. hirsuta with $19.6 \mathrm{MJ} \mathrm{kg}^{-1}$ (Table 2). That value was $13 \%$ higher than that of the $D$. juncea (Table 2 ), the species with the worst calorific performance. The observed $\mathrm{HCV}$ differences among species were equivalent to the LCV differences (Table 2), since the latter is obtained from a direct transformation of the former. The estimated $\mathrm{HCV}$ in this study are within the range reported for native tree-species from Patagonian forests (e.g. Nothofagus pumilio, Austrocedrus chilensis, Nothofagus dombeyi <AQ1>) (Solórzano-Naranjo 2017); and doubled those from certain Patagonian steppe native shrubs commonly used as fuels (e.g. Berberis microphylla, Prosopis denudans and Schinus johnstonii) (Cardoso et al. 2015). Of the species analysed, only the LCV of $N$. antarctica was found in the literature (Solórzano-Naranjo 2017) and was similar to that obtained in this study. According to our results, the woody species of northern Patagonian shrublands have similar calorific values to those of the main tree species planted for bioenergy in Mediterranean regions, such as the Salix spp. and Populus spp. (Senelwa and Sims 1999; Klasnja et al. 2010).

The energy density observed in $N$. antarctica was about $19 \%$ higher than that in E. coccineum, the species with the lowest value. The other species did not statistically differ from these two (Table 2). This result is interesting, since the $N$. antarctica is the most dominant species in these shrublands, and it is present in northern Patagonian mix formation and pure shrublands (Reque et al. 2007). Energy density is an important parameter, because it expresses the amount of energy per unit of volume; that is, it combines calorific value with wood density. The high energy density observed in shrubland native species is mainly due to the high density of their wood. These species have high density when compared to those used under short-rotation forestry (Klasnja et al. 2010), suggested to be economically efficient; since the amount of transported energy increases (i.e. unit costs are reduced) with wood density (Demirba 1997). Since volume is commonly the unit of reference in the region's wood market, the information generated in this study can be useful in defining differential prices of firewood.

When combined, the previous energy parameter results in FVI. According to this index, the E. coccineum (FVI $\approx 6$ 964, Table 2) provides the best fuel properties, mainly because of its low ash content. This is particularly relevant for industrial use, because ash accumulation entails slag formation and corrosion, affecting the thermal conversion process at large-scale (Ngangyo-Heya et al. 2019). Furthermore, it is troublesome for domestic use because it increases the maintenance costs of boilers and heaters (Ngangyo-Heya et al. 2016). The FVI of the L. hirsuta did not significantly differ from that of the E. coccineum (Table 2); but unlike the latter, the relatively high value conformed with the combined effect of all the wood energy properties (Table 2). The FVI found in all the 
species analysed was higher, or at least as high as that observed in the Patagonian steppe native shrubs commonly used as fuel (Cardoso et al. 2015).

\section{Biomass and bioenergy stock estimations}

Northern Patagonian shrublands are diverse ecosystems and usually form complex structures with difficult biomass stock estimations. With the biomass equations we could estimate biomass stock of three contrasting shrublands (Table 3). Other works have discussed the differences between biomass productivity in these contrasting sites (Coulin et al. 2019, Goldenberg et al. unpubl. data), but in this work biomass stock was estimated through biomass equations focused on young resprouts. We found that after $\approx 4$ years from intervention the highly productive shrubland produced $\approx 1.07 \mathrm{t} \mathrm{ha}^{-1}$ of dry stem biomass, the medium productivity site produced $\approx 0.34 \mathrm{t} \mathrm{ha}^{-1}$ of dry stem biomass and the low productivity site produced $\approx 0.08 \mathrm{t} \mathrm{ha}^{-1}$ of dry stem biomass. In these estimations there are different sources of variation: number of stems per stool, stem dimensions, number of plants resprouting (i.e. plant density) and composition, but with the biomass equations developed in this paper, biomass stock estimates are feasible.

Bioenergy stocks range from $1.33 \mathrm{GJ} \mathrm{ha}^{-1}$ to $17.96 \mathrm{GJ} \mathrm{ha}^{-1}$ depending on site conditions (i.e. productivity), plant density and species composition. Bioenergy stock was calculated only from young resprouts so values in Table 3 are an overestimation since calorific values can increase with age and LCV was determined from older non-harvested trees (Eimil-Fraga et al. 2019). Also, calorific value is mainly influenced by moisture content (Aniszewska and Gendek 2014) and LCV was calculated in dry basis so bioenergy stock values in Table 3 represent a reference for future research. Ultimately, bioenergy stock should be determined according to the moisture content of fuel in the moment it is used for burning. Nevertheless, this is the first attempt of quantifying bioenergy contained in coppiced shrublands.

\section{Conclusions}

This study quantified certain aspects of the bioenergy potential of Patagonian shrublands, a relevant issue for Global Change challenges and sustainable development. Bioenergy is directly related to land-use; and historically, forest science has neglected shrubland management. Thus, the information provided in this study is both locally important and relevant to forestry in general.

One of the addressed issues was related to biomass production and was assessed by developing biomass equations for small resprouts of five northern Patagonian native species that performed well as a source of fuel $<A Q 2>$. This information complements that provided in previous studies focused on higher diameter classes; and is an important contribution for biomass stock estimations as showed in three contrasting shrublands (Table 3). Further, it is useful for designing management schemes based on biomass commercialisation and regional energy demands. Through the assessment of wood energy quality, our study demonstrates that the energy properties of the analysed species are comparable to those of other woody species commonly used as fuels, both in northern Patagonia and around the world. The highest calorific values were obtained in $L$. hirsuta and E. coccineum; the latter showing also very low ash content, which favours its fuel properties (fuelwood value index). $N$. antarctica, the species most frequently used as firewood in the region, provides high energy density wood, due to its high density. This fact advantageously positions $N$. antarctica wood as a fuel, since it would reduce energy transport and storage costs (some of the most important factors influencing commercialisation). Finally, energy density was relatively high in all the analysed species, which demonstrates their aptitude for use as an energy source. Therefore, the development and promotion of sustainable management schemes based on energy demands, considering decision makers and social needs, becomes essential in the region.

Table 3: Biomass and bioenergy stock calculation from resprouts of $\approx 4$ years old in three contrasting shrublands. Biomass stock was obtained by multiplying stem dry weight (Figure 2) by mean number of stems per resprouting plant and plant density (Table 1). Bioenergy stock was obtained by multiplying LCV by biomass stock.

\begin{tabular}{|c|c|c|c|c|c|c|}
\hline Site & Species & $\begin{array}{c}\text { Stem } \\
\text { weight } \\
\left(\mathrm{g} \mathrm{st}^{-1}\right)\end{array}$ & $\begin{array}{c}\text { Plant } \\
\text { weigth } \\
\left(\mathrm{g} \mathrm{pl}^{-1}\right) \\
\end{array}$ & $\begin{array}{c}\text { LCV } \\
\left(\mathrm{MJ} \mathrm{kg}^{-1}\right)\end{array}$ & $\begin{array}{c}\text { Biomass } \\
\text { stock } \\
\left(\mathrm{t} \mathrm{ha}^{-1}\right)\end{array}$ & $\begin{array}{c}\text { Bioenergy } \\
\text { stock } \\
\left(\mathrm{GJ} \mathrm{ha}^{-1}\right)\end{array}$ \\
\hline \multirow{5}{*}{$\mathrm{H}$} & N. antarctica & 32.33 & 323.28 & 16.6 & \multirow{5}{*}{1.07} & \multirow{5}{*}{17.96} \\
\hline & L. hirsuta & 61.38 & 938.67 & 18.3 & & \\
\hline & S. patagonicus & 44.03 & 782.93 & 16.8 & & \\
\hline & D. juncea & 65.77 & 1543.27 & 16.0 & & \\
\hline & E. coccineum & 32.45 & 360.53 & 17.6 & & \\
\hline \multirow{5}{*}{ M } & N. antarctica & 28.44 & 352.50 & 16.6 & \multirow{5}{*}{0.34} & \multirow{5}{*}{5.66} \\
\hline & L. hirsuta & 17.60 & 295.49 & 18.3 & & \\
\hline & S. patagonicus & 17.42 & 254.04 & 16.8 & & \\
\hline & D. juncea & 69.10 & 594.64 & 16.0 & & \\
\hline & E. coccineum & 22.76 & 318.63 & 17.6 & & \\
\hline $\mathrm{L}$ & N. antarctica & 5.53 & 37.63 & 16.6 & 0.08 & 1.33 \\
\hline
\end{tabular}

${ }^{*} \mathrm{H}$ and $\mathrm{M}$ had the same species composition but differed in plant density. 
Acknowledgments - We are grateful to the private forest owners for allowing us to collect the samples and install the experiments in their fields. Thanks also go to Ing. Pablo E. Martina of the Department of Thermodynamics Universidad Nacional del Nordeste. This work was funded by Agencia Nacional de Promoción Científica y Tecnológica - Argentina (PICT 2013-1079 and PICT 2016-0305), Universidad Nacional de Río Negro (PI40-B-399) and a CONICET fellowship to the first author.

\section{References}

Abbasi T, Abbasi SA. 2010. Biomass energy and the environmental impacts associated with its production and utilization. Renewable and Sustainable Energy Reviews 14: 919-937. https://doi. org/10.1016/j.rser.2009.11.006

Abbot PG, Lowore JD. 1999. Characteristics and management potential of some indigenous firewood species in Malawi, Forest Ecology and Management 119: 111-121.

Andreassi L, Diez JP, Claps L, Varela S, Martinez-Meier A, Caballe G, Salvaré F. 2017. Estudio de la oferta de bioenergía y aprovechamiento integral maderero proveniente de plantaciones de pinus. Oral presentation in Primeras jornadas nacionales sobre dendrocombustibles y dendroenergías, Chaco.

Aniszewska M, Gendek A. 2014. Comparison of heat of combustion and calorific value of the cones and wood of selected forest trees species. Leśne Prace Badawcze, 75: 231-236. https://doi.org/10.2478/frp-2014-0022

Barton K. 2018. Multi-Model Inference (1). Retrieved from https:// cran.r-project.org/web/packages/MuMIn/MuMln.pdf

Blackhall M, Raffaele E, Veblen TT. 2012. Is foliar flammability of woody species related to time since fire and herbivory in northwest Patagonia, Argentina? Journal of Vegetation Science 23: 931-941. https://doi.org/10.1111/j.1654-1103.2012.01405.x

BUN-CA. 2002. Manuales sobre energía renovable: Biomasa/ Biomass Users Network (BUN-CA). 1st ed. San José, C.R.: Biomass Users Network.

Cardoso MB, Ladio AH, Dutrus SM, Lozada M. 2015. Biomass and bioenergy preference and calorifc value of fuelwood species in rural populations in northwestern Patagonia. Biomass and Bioenergy 81: 514-520.

Carmona-Cerda C, Alvaro-Urzua M. 2013. Caracterización de biomasa leñosa con fines energéticos disponible en Chile.

Cienciala E, Černý M, Apltauer J, Exnerová Z. 2015. Biomass functions applicable to European beech. Journal of Forest Science 51: 147-154. https://doi.org/10.17221/4553-JFS

Coulin C, Aizen MA, Garibaldi LA. 2019. Contrasting responses of plants and pollinators to woodland disturbance. Austral Ecology. https://doi.org/10.1111/aec.12771

Demirba A. 1997. Calculation of higher heating values of biomass fuels. Fuel 76: 431-434.

Eimil-Fraga C, Proupín-Castiñeiras X, Rodríguez-Añón JA, Rodríguez-Soalleiro R. 2019. Effects of shoot size and genotype on energy properties of poplar biomass in short rotation crops. Energies 12: 2051. https://doi.org/10.3390/en12112051FAO. 2017. Woodfuels handbook.

Garibaldi LA, Aristimuño FJ, Oddi FJ, Tiribelli T. 2017. Inferencia multimodelo en ciencias sociales y ambientales. Ecologia Austral 27(3): 348-363. https://doi.org/10.25260/EA.17.27.3.0.513.

Gargaglione V, Peri P, Rubio G. 2010. Allometric relations for biomass partitioning of Nothofagus antarctica trees of different crown classes over a site quality gradient. Forest Ecology and Management 259: 1118-1126. https://doi.org/10.1016/j. foreco.2009.12.025

Goldenberg MG, Gowda JH, Casas C, Garibaldi LA. 2018. Discount rate effect on the prioritization of management alternatives in North-Patagonia Argentinian shrubland. Bosque, 39(2): 217-226.
https://doi.org/10.4067/S0717-92002018000200217

González-González BD, Sixto H, Alberdi I, Esteban L, Guerrero S, Pasalodos M, Cañellas I. 2017. Estimation of shrub biomass availability along two geographical transects in the Iberian Peninsula for energy purposes. Biomass and Bioenergy 105: 211-218. https://doi.org/10.1016/j.biombioe.2017.07.011

Gowda JH. 2013. ¿ Qué protegemos y qué deberíamos proteger con la ley de bosques? Aportes para la primera revisión del ordenamiento territorial de los bosques de Río Negro. Revista de la Asociación Argentina de Ecología del Paisaje 4: 46-62.

Grosfeld J, Chauchard L, Gowda JH. 2019. Debates: ¿ Podemos manejar sustentablemente el bosque nativo de Patagonia Norte? Ecología Austral 29(1): 156-63

Gyenge J, Elena M, Sarasola M, Urquiza M. De, Schlichter T. 2009. Ecuaciones para la estimación de biomasa aérea y volumen de fuste de algunas especies leñosas nativas en el valle del río Foyel, NO de la Patagonia argentina. Bosque 30: 95-101. https://doi.org/10.4067/S0717-92002009000200005

Hilbert JA. 2013. Producción Forestal. Producción Forestal 3(5): 1-44.

Huber JA, May K, Willow AÁ. 2017. Allometric tree biomass models of various species grown in short-rotation agroforestry systems. European Journal of Forest Research 136: 75-89. https://doi. org/10.1007/s10342-016-1010-7

Joosten R, Schumacher J, Wirth C, Schulte A. 2004. Evaluating tree carbon predictions for beech (Fagus sylvatica L.) in western Germany. Forest ecology and management 189: 87-96. https:// doi.org/10.1016/j.foreco.2003.07.037

Karp A, Shield I. 2014. Bioenergy from plants and the sustainable yield challenge. New Phytologist 179: 15-32. https://doi. org/10.1111/j.1469-8137.2008.02432.x

Kauter D, Lewandowski I, Claupein W. 2003. Quantity and quality of harvestable biomass from Populus short rotation coppice for solid fuel use - a review of the physiological basis and management in uences. Biomass and Bioenergy 24: 411-427.

Keeley JE, Pausas JG, Rundel PW, Bond WJ, Bradstock RA. 2011. Fire as an evolutionary pressure shaping plant traits. Trends in Plant Science 16: 406-411. https://doi.org/10.1016/j. tplants.2011.04.002

Kitzberger T, Veblen TT. 1999. Fire-induced changes in northern Patagonian landscapes. Landscape Ecology 14(1): 1-15. https:// doi.org/10.1023/A:1008069712826

Klasnja B, Kopitovic S, Orlovic S. 2010. Wood and bark of some poplar and willow clones as fuelwood. Biomass and Bioenergy 23, 427-432.

Ngangyo-Heya M, Foroughbakhch Pournavab R, Carrillo Parra A, Zelinski V, Salas Cruz LR. 2019. Elemental composition and flue gas emissions of different components from five semi-arid woody species in pyrolysed and non-pyrolysed material. Sustainability 11: 1245. https://doi.org/10.3390/su11051245

Olesen PO. 1971. The Water Displacement Method. A fast and accurate method of determining the green volume of wood samples. The Royal Veterinary and Agricultural University of Copenhagen.

Panwar NL, Kaushik SC, Kothari S. 2011. Role of renewable energy sources in environmental protection: A review. Renewable and Sustainable Energy Reviews 15(3): 1513-1524. https://doi. org/10.1016/j.rser.2010.11.037

Pinheiro J, Bates D, DebRoy S, Sarkar D, Team RC. 2018 nlme: Linear and Nonlinear Mixed Effects Models. https://cran.r-project. org/package=nlme.

Purohit AN, Nautiyal AR. 1984. Fuelwood value index of Indian mountain tree species. International Tree Crops Journal $4(2 / 3)$ : 37-41. https://doi.org/10.1080/01435698.1987.9752821. <AQ3>

Ragland KW, Aerts DJ, Service UF. 1991. Properties of Wood for Combustion Analysis. Bioresources Technology 37: 161-168.

R Core Team. 2017. Retrieved from https://www.r-project.org

Reque JA, Sarasola M, Elena M. 2007. Silvicultural characterization 
of the mixed ñire forests of northern Patagonia as a basis for sustainable forestry. Bosque 28: 33-45.

Schlichter T, Laclau P. 1998. Ecotono estepa-bosque y plantaciones forestales en la Patagonia norte. Ecologia Austral 8: 285-296.

Senelwa K, Sims REH. 1999. Fuel characteristics of short rotation forest biomass. Biomass and Bioenergy 17: 127-140.

Singh B, Khanduja SD. 1984. Wood properties of some firewood shrubs in northern India. Biomass and Bioenergy 4: 235-238.

Solórzano-Naranjo S. 2017. Herramienta para negocios sustentables en biomasa forestal región de Aysén. Informe Técnico $\mathrm{N}^{\circ} 214$.

Speziale K.L, Ruggiero A, Ezcurra C. 2010. Plant species richnessenvironment relationships across the Subantarctic-Patagonian transition zone. Journal of Biogeography 37(3): 449-464. https:// doi.org/10.1111/j.1365-2699.2009.02213.x

Tiribelli F, Kitzberger T, Manuel J. 2018. Changes in vegetation structure and fuel characteristics along post-fire succession promote alternative stable states and positive fire-vegetation feedbacks. Journal of Vegetation Science. 29(2): 147-156. https://doi.org/10.1111/jvs.12620

Wirth C, Schumacher J, Schulze E. 2004. Generic biomass functions for Norway spruce in Central Europe - a meta-analysis approach toward prediction and uncertainty estimation. Tree Physiology 24(2): 121-139. 